\title{
RESPONSE SURFACE METHODOLOGY FOR EFFECTIVE LUBRICATION AND REDUCED TOOL WEAR IN TURNING EN24 STEEL
}

\author{
ADALARASAN R. ${ }^{*}$, SANTHANAKUMAR M. ${ }^{1}$ \\ 1Department of Mechanical Engineering, Saveetha Engineering College, Chennai, Tamilnadu, India \\ Email: 1adalarasan@saveetha.ac.in
}

\begin{abstract}
Turning is an important machining process involving quality characteristics like tool wear and finish of the cut surface. The present work is focused towards the application of response surface methodology (RSM) in turning of EN24 steel. The work observes the effectiveness of the application of minimum quality lubricant (MQL) during the process of turning EN24 steel. The selection of parameters like tool type, work speed, depth of cut and type of lubrication is vital to obtain a good finish and reduced tool wear. Taguchi's $L_{18}$ orthogonal array $(O A)$ is used to conduct the turning trials and RSM is applied to predict the optimal turning condition.
\end{abstract}

Key words: EN24 steel; Optimization; response surface methodology; Taguchi; Surface finish.

\section{INTRODUCTION}

The EN24 steel finds many applications requiring high strength and wear resistance. The growing industrial application requires a proper study of their machining characteristics. Turning is an important metal removal operation for fabrication of parts in the final stage. However the difficulty in turning EN24 steel has created a good degree of research interest and hence the required drive and motivation. Generally the flank wear of the tool is found to be more at higher cutting speed and feed rate [1]. The effect of various machining parameters can be visualized from the quality characteristics observed in the machined surfaces including tool wear [2-5].

The methods used for solving the multi response problems include the principal component analysis (PCA), grey relational analysis (GRA), technique for order of preference by similarity to ideal solution (TOPSIS), neural networks, genetic algorithm (GA), response surface methodology (RSM) and desirability analysis [610]. Taguchi's technique employing the concepts of the grey theory is effectively used to identify the grey relational grade. It is used as the performance measure to find the optimal setting of input parameters [11, 12]. Taguchi based method is found to be effective in single response optimization, however a practical situation requires multi response optimization [13, 14]. Taguchi based desirability analysis is observed to predict the optimal variables in different manufacturing operations $[15,16]$. The hybrid technique of grey based PCA can be applied to solve problems with a finite number of options. It combines the merits of both the techniques adopted for prediction of optimal variables [17]. The response surface methodology is a numerical technique employed along with the desirability analysis to find the optimal input condition. The technique is used to generate the desirability plots and identify the relation between the variables and observed quality characteristics $[18,19]$.

From the review of literature, it is observed that optimization of the turning characteristics and a study of lubrication effectiveness is limited in literature, particularly with EN24 steel. Hence the present work is focused towards applying the RSM to identify the optimal turning condition for EN24 steel.

\section{EXPERIMENTATION AND DESIGN OF TURNING TRIALS}

The EN24 steel rods of diameter $25 \mathrm{~mm}$ are subjected to turning under defined conditions. A center lathe with required accessories and attachments is used for experimentation and a new insert is used during different trials. The input parameters like type of lubrication, tool type, work speed and depth of cut is taken for the study and their levels are found out by pilot trials. The number of input variables and their levels are indicated in Table 1. 
Taguchi $L_{18}$ orthogonal array is used to conduct the turning trials and two replicates are obtained for each of the responses. The responses like tool wear and surface finish are studied as the quality characteristics. The surface finish is measured by using Talysurf recorder for a cut-off length of $0.8 \mathrm{~mm}$. The width of the flank wear land is observed to evaluate the wear of the tool using a video measuring system inbuilt with a high resolution camera. The responses obtained during the trials are listed in Table 2. The trials were conducted randomly to reduce the effects of extraneous factors available during experimentation.

Table 1. Variables and their levels

\begin{tabular}{|c|c|c|c|c|}
\hline Symbol & $\begin{array}{c}\text { Input } \\
\text { Parameters }\end{array}$ & Level 1 & Level 2 & Level 3 \\
\hline A & Tool type & WC insert & TiN insert & - \\
\hline B & $\begin{array}{c}\text { Type of } \\
\text { lubrication }\end{array}$ & $\begin{array}{c}\text { Dry } \\
\text { machining }\end{array}$ & $\begin{array}{c}\text { Conventional } \\
\text { lubrication }\end{array}$ & MQL \\
\hline C & $\begin{array}{c}\text { Work speed } \\
\text { (rpm) }\end{array}$ & 200 & 400 & 600 \\
\hline D & $\begin{array}{c}\text { Depth of cut } \\
\text { (mm) }\end{array}$ & 0.4 & 0.6 & 0.8 \\
\hline
\end{tabular}

Table 2. L18 OA and responses

\begin{tabular}{|c|c|c|c|c|c|c|}
\hline \multirow{2}{*}{ Trials } & \multicolumn{3}{|c|}{ Parameters } & \multicolumn{2}{c|}{ outputs } \\
\cline { 2 - 7 } & A & B & C & D & $\begin{array}{c}\text { Surface } \\
\text { roughness } \\
(\boldsymbol{\mu m})\end{array}$ & $\begin{array}{c}\text { Flank } \\
\text { wear } \\
(\mathrm{mm})\end{array}$ \\
\hline 1 & 1 & 1 & 1 & 1 & 0.693 & 0.0376 \\
\hline 2 & 1 & 1 & 2 & 2 & 0.706 & 0.0372 \\
\hline 3 & 1 & 1 & 3 & 3 & 0.722 & 0.0421 \\
\hline 4 & 1 & 2 & 1 & 1 & 0.663 & 0.0342 \\
\hline 5 & 1 & 2 & 2 & 2 & 0.689 & 0.0362 \\
\hline 6 & 1 & 2 & 3 & 3 & 0.726 & 0.0393 \\
\hline 7 & 1 & 3 & 1 & 2 & 0.674 & 0.0356 \\
\hline 8 & 1 & 3 & 2 & 3 & 0.640 & 0.0375 \\
\hline 9 & 1 & 3 & 3 & 1 & 0.626 & 0.0373 \\
\hline 10 & 2 & 1 & 1 & 3 & 0.678 & 0.0376 \\
\hline 11 & 2 & 1 & 2 & 1 & 0.682 & 0.0346 \\
\hline 12 & 2 & 1 & 3 & 2 & 0.662 & 0.0358 \\
\hline 13 & 2 & 2 & 1 & 2 & 0.615 & 0.0367 \\
\hline 14 & 2 & 2 & 2 & 3 & 0.652 & 0.0382 \\
\hline 15 & 2 & 2 & 3 & 1 & 0.632 & 0.0352 \\
\hline 16 & 2 & 3 & 1 & 3 & 0.572 & 0.0375 \\
\hline 17 & 2 & 3 & 2 & 1 & 0.521 & 0.0366 \\
\hline 18 & 2 & 3 & 3 & 2 & 0.543 & 0.0410 \\
\hline & & & & & & \\
\hline
\end{tabular}

\section{RESPONSE SURFACE METHODOLOGY}

The centre-line average surface roughness value $(\mathrm{Ra})$ is generally employed to characterize the turned surface. The tool wear is a measure of machinability. The studied responses are optimized using the various steps listed below.

Step 1: Calculate the $S / N$ ratio as a part of data preprocessing using the lower-the-better characteristic [3].

Step 2: Perform data normalization and calculate the normalized $S / N$ ratio $[4,7]$.

Step 3: Determine the values of grey relational coefficient and grey relational grade (GRG) by taking appropriate value of distinguishing coefficient $[8,11]$.

Step 4: Find the mathematical relationship between the turning variables and GRG to study the behaviour in experimental domain [18].

Step 5: Supplement with proper analysis of variance (ANOVA) to find the contribution of turning parameters [3, 9].

Step 6: Plot the 3D graphs to observe the influence of turning variables on responses and apply the desirability analysis.

\section{RESULTS AND DISCUSSION}

A. Conversion of responses (surface roughness and flank wear) into GRG

The $\mathrm{S} / \mathrm{N}$ ratio and normalized $\mathrm{S} / \mathrm{N}$ ratio are found out as a part of data pre-processing. Both the tool wear and surface roughness are analyzed as smaller-the-better responses with a desired target of zero. The values of normalized $S / N$ ratio and GRG are listed in Table 3. The calculation of GRG value permits the conversion of a multi response optimization problem into optimization of a single response.

\section{B. Mathematical modelling}

The quadratic models (polynomial equations of second order) are generated to indicate the mathematical relationship between turning variables and responses. The quadratic model relates the responses in terms of GRG with the turning variables. A L18 OA is used to reduce the number of machining trials. The design expert software is used to generate the models (Equations (16)). 
Tool type $\quad:$ WC insert

Type of lubrication : Dry machining

Table 3. Normalization and GRG values

\begin{tabular}{|c|c|c|c|c|c|c|c|}
\hline \multirow{2}{*}{ Trials } & \multicolumn{2}{|c|}{ S/N ratio } & \multicolumn{2}{c|}{ Normalized S/N ratio } & \multicolumn{2}{c|}{ Grey relational coefficient } & \multirow{2}{*}{ GRG } \\
\cline { 2 - 7 } & Ra & FW & Ra & FW & Ra & FW & \\
\hline 1 & 3.185 & 28.496 & 0.140 & 0.544 & 0.368 & 0.523 & 0.445 \\
\hline 2 & 3.024 & 28.589 & 0.084 & 0.595 & 0.353 & 0.553 & 0.453 \\
\hline 3 & 2.829 & 27.514 & 0.017 & 0.000 & 0.337 & 0.333 & 0.335 \\
\hline 4 & 3.570 & 29.319 & 0.274 & 1.000 & 0.408 & 1.000 & 0.704 \\
\hline 5 & 3.236 & 28.826 & 0.158 & 0.727 & 0.372 & 0.646 & 0.509 \\
\hline 6 & 2.781 & 28.112 & 0.000 & 0.331 & 0.333 & 0.428 & 0.381 \\
\hline 7 & 3.427 & 28.971 & 0.224 & 0.807 & 0.392 & 0.721 & 0.557 \\
\hline 8 & 3.876 & 28.529 & 0.380 & 0.562 & 0.446 & 0.533 & 0.490 \\
\hline 9 & 4.069 & 28.566 & 0.447 & 0.582 & 0.475 & 0.545 & 0.510 \\
\hline 10 & 3.375 & 28.496 & 0.206 & 0.544 & 0.386 & 0.523 & 0.455 \\
\hline 11 & 3.324 & 29.213 & 0.188 & 0.941 & 0.381 & 0.895 & 0.638 \\
\hline 12 & 3.583 & 28.922 & 0.278 & 0.780 & 0.409 & 0.694 & 0.552 \\
\hline 13 & 4.222 & 28.707 & 0.500 & 0.661 & 0.500 & 0.596 & 0.548 \\
\hline 14 & 3.715 & 28.359 & 0.324 & 0.468 & 0.425 & 0.484 & 0.455 \\
\hline 15 & 3.986 & 29.069 & 0.418 & 0.861 & 0.462 & 0.783 & 0.622 \\
\hline 16 & 4.852 & 28.519 & 0.719 & 0.557 & 0.640 & 0.530 & 0.585 \\
\hline 17 & 5.663 & 28.730 & 1.000 & 0.674 & 1.000 & 0.605 & 0.753 \\
\hline 18 & 5.304 & 27.744 & 0.875 & 0.127 & 0.800 & 0.364 & 0.582 \\
\hline
\end{tabular}

$\mathrm{GRG}=+0.39256+6.09196 \mathrm{E}-004 *$ Work speed 0.098977 * Depth of cut +2.99037E-004 * Work speed * Depth of cut $-1.27442 \mathrm{E}-006$ * Work speed $^{2}$

Tool type

: WC insert

Type of lubrication : Conventional machining

$\mathrm{GRG}=+0.89832+6.09196 \mathrm{E}-004$ * Work speed -0.75428

* Depth of cut $+2.99037 \mathrm{E}-004^{*}$ Work speed *

Depth of cut $-1.27442 \mathrm{E}-006$ * Work speed ${ }^{2}$

Tool type

:WC insert

Type of lubrication : MQL

GRG $=+0.76446+6.09196 \mathrm{E}-004$ * Work speed 0.53218 * Depth of cut +2.99037E-004 * Work speed * Depth of cut $-1.27442 \mathrm{E}-006{ }^{*}$ Work speed $^{2}$

Tool type

: TiN insert

Type of lubrication : Dry machining

GRG $=+0.59343+6.09196 \mathrm{E}-004 \quad *$ Work speed 0.098977 * Depth of cut +2.99037E004 * Work speed * Depth of cut $-1.27442 E-006$ * Work speed $^{2}$
Tool type : : TiN insert

Type of lubrication : Conventional machining

GRG $=+0.92069+6.09196 \mathrm{E}-004 *$ Work speed $0.75428 *$ Depth of cut +2.99037E-004

Work speed * Depth of cut $-1.27442 \mathrm{E}-006$ * Work speed $^{2}$

(5)

Tool type

: TiN insert

Type of lubrication : MQL

$\mathrm{GRG}=+0.90236+6.09196 \mathrm{E}-004$ * Work speed -0.53218 * Depth of cut +2.99037E-004 * Work speed * Depth of cut $-1.27442 \mathrm{E}-006$ * Work speed ${ }^{2}$

\section{Fitness and adequacy}

.The analysis of variance is performed on the GRG (Table 4) and F-ratio test results are presented to prove model adequacy. The model F-value (14.13) proves its significance. The probability of model $\mathrm{F}$-value reaching higher value due to noise factors is about $0.01 \%$. The influence of various model terms is proved by the $p$-value in the ANOVA table. The insignificant terms are removed from the model during reduction. 
Table 4. Analysis of variance

\begin{tabular}{|l|c|c|c|c|c|c|}
\hline \multicolumn{1}{|c|}{ Source } & $\begin{array}{c}\text { Sum of } \\
\text { squares }\end{array}$ & $\begin{array}{c}\text { Degrees } \\
\text { of } \\
\text { freedom }\end{array}$ & $\begin{array}{c}\text { Mean sum } \\
\text { of square }\end{array}$ & F-value & p-value & Remarks \\
\hline Model & 0.21 & 11 & 0.019 & 14.13 & 0.002 & significant \\
\hline A-Tool type & 0.044 & 1 & 0.044 & 32.63 & 0.0012 & \\
\hline B-Type of lubrication & 0.024 & 2 & 0.012 & 8.85 & 0.0162 & \\
\hline C-Work speed & 0.019 & 1 & 0.019 & 14.04 & 0.0095 & \\
\hline D-Depth of cut & 0.06 & 1 & 0.06 & 44.58 & 0.0005 & \\
\hline AB & 0.019 & 2 & $9.64 \mathrm{E}-03$ & 7.11 & 0.0261 & \\
\hline BD & 0.023 & 2 & 0.012 & 8.56 & 0.0175 & \\
\hline CD & $6.55 \mathrm{E}-04$ & 1 & $6.55 \mathrm{E}-04$ & 0.48 & 0.5129 & \\
\hline C $^{2}$ & $8.96 \mathrm{E}-03$ & 1 & $8.96 \mathrm{E}-03$ & 6.62 & 0.0422 & \\
\hline Residual & $8.13 \mathrm{E}-03$ & 6 & $1.36 \mathrm{E}-03$ & & & \\
\hline Cor Total & 0.22 & 17 & & & & \\
\hline
\end{tabular}

The value of R-squared is $96.28 \%$ and it proves the closeness among the values predicted by the mathematical model and the experimental data (Table 5). The higher R-squared value indicates the accuracy of model coefficients. The predicted R-squared value and adjusted R-squared value are in realistic agreement with each other. Hence the polynomial equation can be deemed fit and adequately precise in predicting the responses. The response surface plots

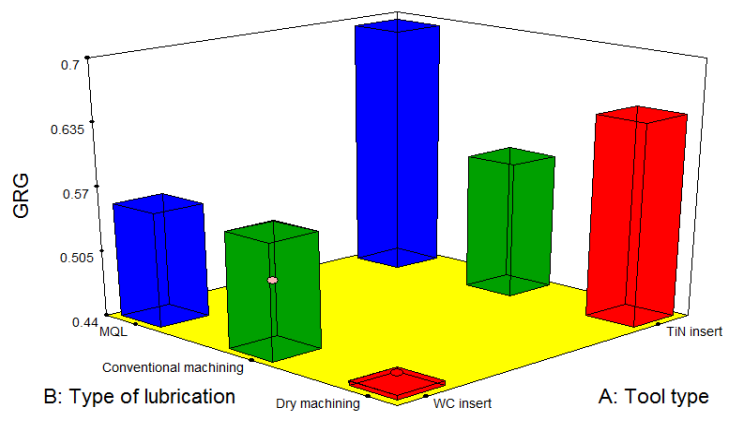

(a) are generated to study the effect of turning variables on the GRG (Figure 1).

Table 5. R-squared and adequate precision table

\begin{tabular}{|l|c|l|c|}
\hline Std. Dev. & 0.0368 & R-Squared & 0.9628 \\
\hline Mean & 0.5346 & Adj R-Squared & 0.8947 \\
\hline C.V. $\%$ & 6.8852 & Pred R-Squared & 0.5484 \\
\hline PRESS & 0.0988 & Adeq Precision & 14.3718 \\
\hline
\end{tabular}

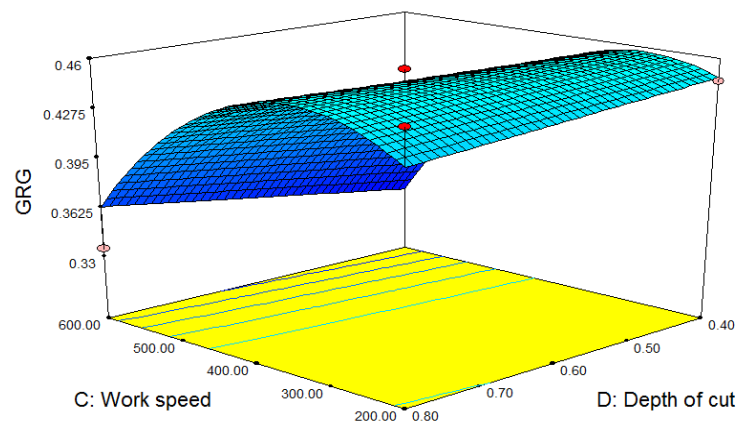

(b)

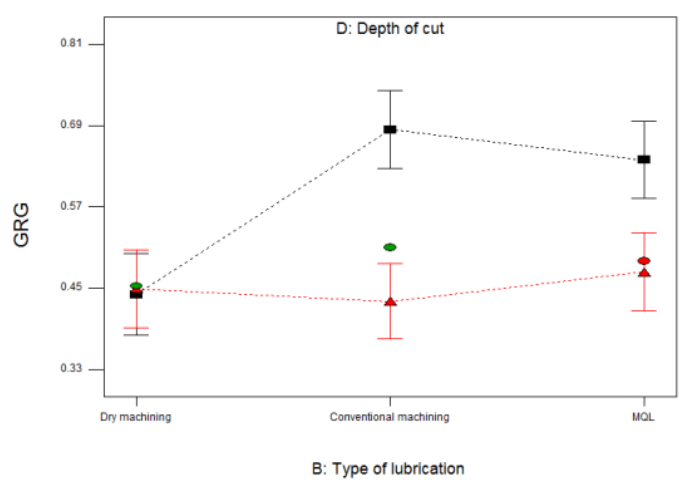

(c)

Fig. 13D plots 
D. Desirability analysis

The larger-the-better type desirability function is used in the analysis with GRG values. The turning condition representing the largest value of desirability is chosen as the optimal condition (Table 6). The optimal turning parameters is found out as: lubrication type: MQL, Tool type: TiN insert, work speed: $285.73 \mathrm{rpm}$ and depth of cut: $0.4 \mathrm{~mm}$. The ramp graph of desirability displays the necessary level of turning parameters (Figure 2). A dot on each ramp and its height indicates the amount of desirability. The optimal value located at the top ascending part of ramp graph and it represents a desirability value of one. In Figure 3 , most of the values appear close to the center line indicating the normal distribution of errors.
Table 6 Optimal turning condition

\begin{tabular}{|c|l|c|c|c|}
\hline Factor & Name & Level & Low Level & $\begin{array}{c}\text { High } \\
\text { Lev } \\
\text { el }\end{array}$ \\
\hline A & Tool type & $\begin{array}{c}\text { TiN } \\
\text { insert }\end{array}$ & WC insert & $\begin{array}{c}\text { TiN } \\
\text { inser } \\
t\end{array}$ \\
\hline B & $\begin{array}{c}\text { Type of } \\
\text { lubrication }\end{array}$ & MQL & $\begin{array}{c}\text { Dry } \\
\text { machining }\end{array}$ & MQL \\
\hline C & Work speed & 285.73 & 200 & 600 \\
\hline D & Depth of cut & 0.4 & 0.4 & 0.8 \\
\hline $\begin{array}{c}\text { Respon } \\
\text { se }\end{array}$ & Prediction & $\begin{array}{c}\text { SE } \\
\text { Mean }\end{array}$ & $\mathbf{9 5 \%}$ Cl low & $\begin{array}{c}\mathbf{9 5 \%} \\
\text { Cl } \\
\text { high }\end{array}$ \\
\hline GRG & 0.7937 & 0.036 & 0.7 & 0.88 \\
\hline
\end{tabular}

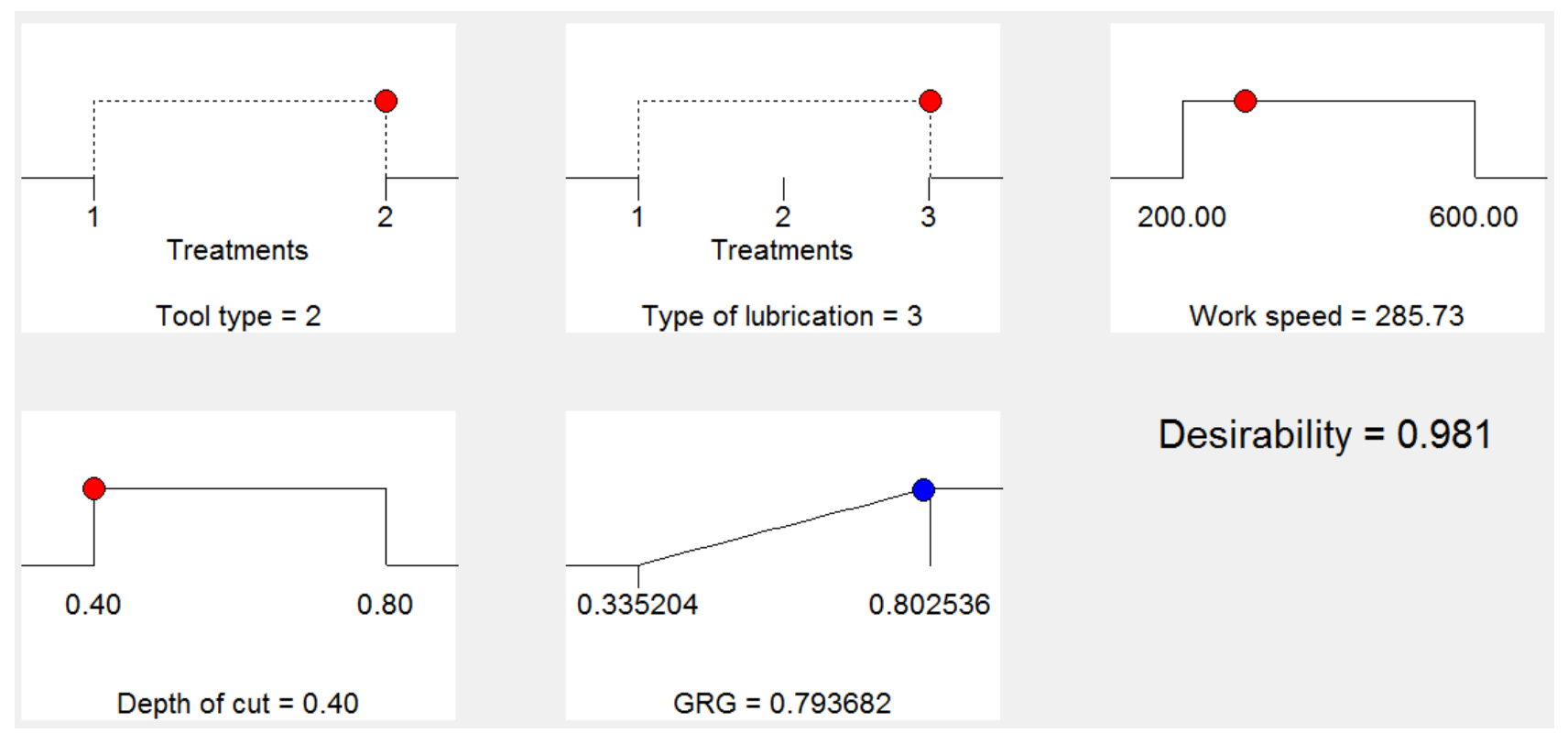

Fig. 2 Desirability graph 


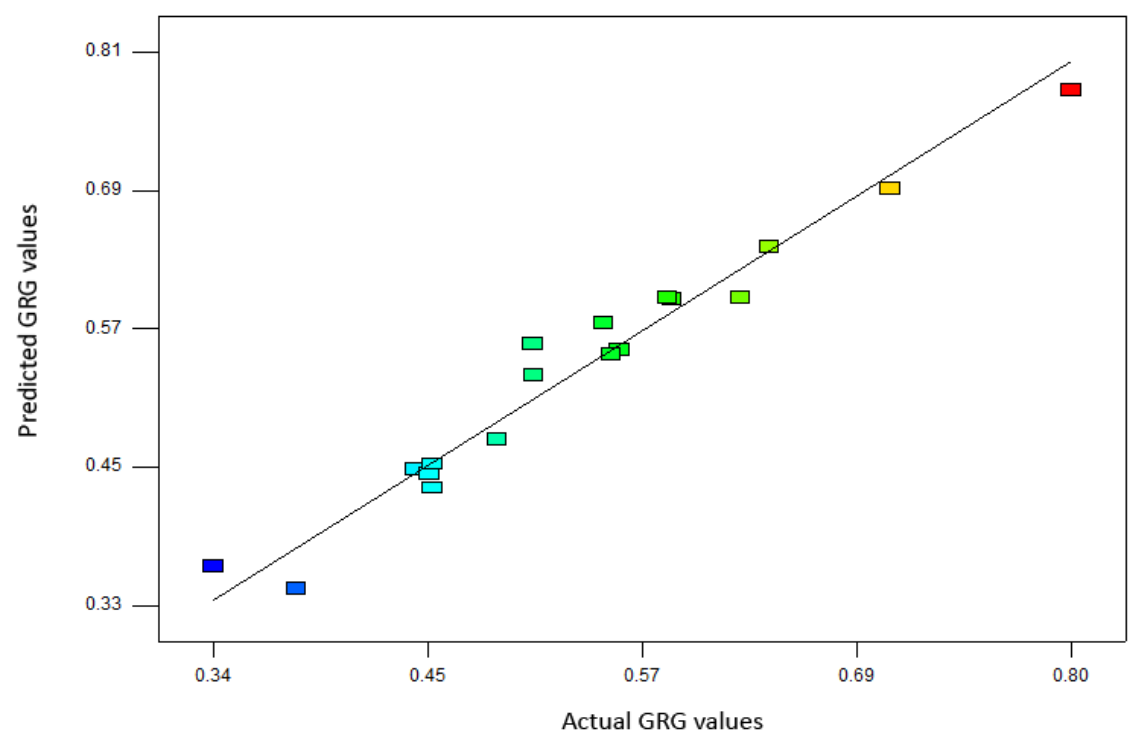

Fig. 3 predicted vs actual GRG values

\section{CONCLUSION}

The paper discloses the application of RSM to the process of machining (turning) of EN24 steel. The following conclusions are drawn.

- The methodology has combined the merits of GRA and RSM, hence requiring a simple computational effort.

- The optimal combination predicted by RSM is lubrication type: MQL, Tool type: TiN insert, work speed: $285.73 \mathrm{rpm}$ and depth of cut: $0.4 \mathrm{~mm}$

- ANOVA is performed on GRG value to find the major input variables affecting the quality characteristics.

The optimal parameter combination can produce a good finish with a reduced tool wear. Hence this method can be applied to solve multi criteria decision making problems.

\section{REFERENCES}

[1] Adalarasan. R., Santhanakumar. M., 2015, Application of Taguchi based Response Surface Method (TRSM) for Optimization of Multi Responses in Drilling $\mathrm{Al} / \mathrm{SiC}_{\mathrm{A}} \mathrm{Al}_{2} \mathrm{O}_{3}$ Hybrid Composite, Journal of the Institution of Engineers (India): Series C, 96 (1), pp. 65-71.

[2] Adalarasan. R., Santhanakumar. M., Rajmohan. M., 2015, Optimization of laser cutting parameters for Al6061/SiCp/Al2O3 composite using grey based response surface methodology (GRSM), Measurement, 73, pp. 596606.
[3] Santhanakumar. M., Adalarasan. R., Rajmohan. M., 2015, Parameter design in plasma arc cutting of galvanised iron sheet using desirability function based response surface methodology (DRSM), International Journal of Manufacturing Research, 10 (3), pp. 199-214.

[4] Adalarasan. R., Santhanakumar. M., Rajmohan. M., 2014, Application of desirability analysis for optimizing the micro wire electrical discharge machining ( $\mu$ WEDM) parameters, Applied Mechanics and Materials, 592-594, pp. 77-81.

[5] Santhanakumar. M., Adalarasan. R., Rajmohan. M., 2015, Experimental Modelling and Analysis in Abrasive Waterjet Cutting of Ceramic Tiles Using Grey-Based Response Surface Methodology, Arabian Journal for Science and Engineering, 40 (11), pp. 3299-3311.

[6] Adalarasan. R., Shanmuga Sundaram. A., 2015, Parameter design in friction welding of $\mathrm{Al} / \mathrm{SiC} / \mathrm{Al} 2 \mathrm{O} 3$ composite using grey theory based principal component analysis (GT-PCA), Journal of the Brazilian Society of Mechanical Sciences Engineering, 37 (5), pp. 1515-1528.

[7] Santhanakumar. M., Adalarasan. R., 2014, Application of Grey Taguchi based Response Surface Methodology (GTRSM) in Injection Moulding of Polypropylene/E-glass Composite, International Journal of Manufacturing, Materials, and Mechanical Engineering, 5 (1), pp. 35-48.

[8] Adalarasan. R., Shanmuga Sundaram, A., 2015, Parameter design and analysis in continuous drive friction welding of Al6061/SiCp composites, Journal of Mechanical Science and Technology, 29 (2), pp. 769-776.

[9] Karthikeyan. R., Adalarasan. R., Pai. B.C., 2002, Optimization of Machining Characteristics for $\mathrm{Al} / \mathrm{SiCp}$ Composites using ANN/GA, Journal of Material Science and technology, 18 (1), pp. 47-50.

[10] Santhanakumar. M., Adalarasan. R., Rajmohan. M., Parameter design for cut surface characteristics in 
abrasive waterjet cutting of $\mathrm{Al} / \mathrm{SiC} / \mathrm{Al}_{2} \mathrm{O}_{3}$ composite using grey theory based RSM, Journal of Material Science and technology, 2016, 30 (1), 371-379.

[11] Adalarasan. R., Santhanakumar. M., 2015, Parameter Design in Fusion Welding of AA 6061 Aluminium Alloy Using Desirability Grey Relational Analysis (DGRA) Method, Journal of the Institution of Engineers (India): Series C, 96(1), pp. 57-63.

[12] Santhanakumar. M., Adalarasan. R., 2014, Study of Compression Molding of GFRP using Grey Relational Analysis, International Journal on Design \& Manufacturing Technologies, 8 (1), pp. 36-39.

[13] Adalarasan. R., Santhanakumar. M., Rajmohan. M., 2015, Application of Grey Taguchi-based response surface methodology (GT-RSM) for optimizing the plasma arc cutting parameters of 304L stainless steel, International Journal of Advanced Manufacturing Technology, 78 (1), pp. $1161-1170$.

[14] Adalarasan. R., Santhanakumar. M., Shanmugasundaram. A., 2014, Optimization of Friction Welding Parameters for AA6061-T6/AA2024-T6 Joints Using Taguchi-Simulated Annealing (TSA) Algorithm, Applied Mechanics and Materials, 592-594, pp. 595-599.
[15] Adalarasan. R., Santhanakumar, M., 2014, Study on Friction Welding of Aluminium based Composites using Desirability Analysis, International Journal on Design \& Manufacturing Technologies, 8(1), pp.1-4.

[16] Atul. S.C., Adalarasan. R., Santhanakumar. M., 2015 , Study on Slurry Paste Boronizing of 410 Martensitic Stainless Steel Using Taguchi Based Desirability Analysis (TDA), International Journal of Manufacturing, Materials, and Mechanical Engineering, 5 (3), pp. 64-77.

[17] Adalarasan. R., Santhanakumar. M., Shanmugasundaram, A., 2014, Optimization of weld characteristics of friction welded AA 6061-AA 6351 joints using grey-principal component analysis (G-PCA), Journal of Mechanical Science and Technology, 28 (1), pp. 301-307.

[18] Adalarasan. R., Santhanakumar. M., 2015, Response surface methodology and desirability analysis for optimizing $\mu$-WEDM parameters for $\mathrm{Al} 6351 / 20 \% \mathrm{Al}_{2} \mathrm{O}_{3}$ composite, International Journal of ChemTech Research, 7 (6), pp. 2625-2631.

[19] Adalarasan. R., Santhanakumar. M., Thileepan. S., 2015 Investigation on strength of solid state $\mathrm{Al} 6061 / 30 \% \mathrm{Al}_{2} \mathrm{O}_{3}$ bonds for automotive applications using response surface methodology (RSM), International Journal of Automotive Composites, 1 (4), pp. 364-374. 